\title{
POLÍTICA DE COMPRA E REPOSIÇÃO DE ESTOQUES EM UMA EMPRESA DE PEQUENO PORTE DO RAMO ATACADISTA DE MATERIAIS PARA CONSTRUÇÃO CIVIL
}

\section{INVENTORY PURCHASING AND REPLENISHMENT POLICY FOR A SMALL WHOLESALER COMPANY OF FIXTURES FROM THE BUILDING CONSTRUCTION INDUSTRY}

\author{
Diego Telles Provin ${ }^{1}$; Miguel Afonso Sellitto ${ }^{2}$ \\ ${ }^{1}$ Universidade do Vale do Rio dos Sinos - UNISINOS - São Leopoldo - Brasil \\ diegoprovin@bol.com.br \\ ${ }^{2}$ Universidade do Vale do Rio dos Sinos - UNISINOS - São Leopoldo - Brasil \\ sellitto@unisinos.br
}

\begin{abstract}
Resumo
Este artigo apresenta um estudo de caso sobre Gestão de Estoques em um atacadista no ramo de construção civil. O trabalho foi estruturado a partir de revisões de literaturas sobre os conceitos de Gestão de Estoques. Foram apresentadas as formas de gestão de estoque presentes nas bibliografias e um comparativo com a atual situação dos níveis de estoques da empresa, a fim de propor uma política de estoques. A utilização de estoques é feita durante o tempo de ressuprimento e é importante, pois possibilita um melhor atendimento ao cliente e melhora a competitividade da empresa em relação aos seus concorrentes, porém deve ser gerenciado constantemente para evitar despesas desnecessárias. O método de gestão foi aplicado em quatro produtos de uma linha de louças sanitárias que a empresa possui no seu mix de produtos.
\end{abstract}

Palavras-chave: gestão de estoque; nível de serviço; tempo de ressuprimento; ponto de pedido; lote econômico de compra.

\section{Introdução}

A logística surgiu no meio militar e era comumente utilizada para armazenar os armamentos e mantimentos das tropas dos exércitos, bem com para transportar soldados de um território para outro. Para Ballou (1993), investir em melhorias na logística é uma das formas mais rápidas de obtenção de resultados na atividade empresarial. Com isso torna-se possível a redução de custos de estocagem que podem ser repassados aos clientes representando um aumento da competitividade para a empresa. $\mathrm{O}$ excesso de estoque gera custo, mas baixo estoque gera insatisfação de clientes: o ponto de equilíbrio estaria no centro desses dois extremos que é o principal objetivo de gestores de estoque. Os estoques são fundamentais na atividade empresarial, pois garantem elevados níveis de 
serviço aos clientes. Porém, se forem demasiados, podem se tornar maléficos à saúde financeira das empresas (BALLOU, 2006).

Quando a economia brasileira era governada por altas taxas de inflação, as compras eram geridas da forma "quanto maior ou mais antecipado o estoque, melhor". Altos níveis de estoque eram sinônimos de retorno futuro, pois os preços subiam continuamente e manter valores sob a forma de materiais mostrava-se vantajoso. Hoje a realidade é outra e manter altos níveis de estoques passou a implicar altos custos para a atividade empresarial. Determinar quanto e quando comprar, qual o nível de estoque de segurança e de cobertura é o papel dos gestores de estoque. Alguns itens devem ser tratados de forma diferente, pois tratam de um alto nível de investimentos ou que possuem um grande impacto no faturamento da empresa (BERTAGLIA, 2003). Chopra e Meindl (2003) afirmam que estoque existe na cadeia de suprimento devido a uma inadequação entre suprimento e demanda. Segundo Ballou (1993), o estoque é o amortecedor entre a oferta e a demanda. Gerenciar estoques é equilibrar a disponibilidade de produtos ou serviço, ao consumidor (BALLOU, 2006). Um problema clássico da Engenharia de Produção é a determinação do esquema ótimo de renovação do estoque de uma certa mercadoria, (ALVARENGA; NOVAES, 2000).

$\mathrm{Na}$ economia atual é responsabilidade das empresas determinarem como os serviços logísticos devem ser realizados, previsão de demanda, estocagem, distribuição e outros. Com a evolução das economias mundiais as empresas devem ter grande êxito e eficácia no desempenho de suas atividades, a logística tem um papel fundamental nesse âmbito, pois proporciona melhor aproveitamento dos recursos financeiros das empresas sejam de manufatura ou atacadistas (KUNIGAMI; OSÓRIO, 2009).

Um dos principais aspectos ligados à estratégia logística de uma empresa é a gestão de seus estoques. Para Dias (2005), um dos objetivos de uma empresa que vise o lucro é maximizar o retorno sobre o capital investido, seja em fábricas, equipamentos, financiamentos de vendas, reserva de caixa ou em materiais e estoques. Para o autor, o dinheiro investido em estoques é importante facilitador para a produção e o bom atendimento das vendas.

Outro fator relevante é a gestão das compras, principalmente quando estas afetam a política de estoque. Segundo Ellram e Carr (1994), a função compras escolhe e desenvolve os fornecedores que suportarão a estratégia de produção e o posicionamento competitivo do negócio. Segundo Arnold (1999), os objetivos da função compras são: (i) especificar as aquisições requeridas pela manufatura, em termos de quantidades, exigências funcionais e preços; (ii) comprar segundo estas especificações; (iii) garantir as entregas; e (iv) manter boas relações com potenciais fornecedores.

O objetivo de pesquisa é propor uma política de reposição de estoques e direcionamento de compras e então comparar esta política com os dados de estoques momentâneos, da época da pesquisa. $\mathrm{O}$ alvo de estudo foi uma linha de produtos de um atacadista do ramo de construção civil, 
na qual foi feito um estudo de política de estoques a partir do histórico de vendas da empresa. $\mathrm{O}$ artigo é delimitado ao estudo da demanda de 01/01/2009 a 31/05/2010 da linha Thema da marca Incepa de quatro itens diferentes, fornecidos por uma mesma empresa atacadista, atendida por um único operador de sérvios de transporte. Os dados aqui apresentados foram levantados com autorização da empresa. A pesquisa não possui como objetivo discutir qual a melhor forma de gestão de estoque, nem mesmo contextualizar cada forma de gestão de estoque. A questão de pesquisa é: como construir uma política de reposição de estoque para uma empresa atacadista de materiais de construção civil?

O método da pesquisa foi o estudo de caso. Segundo Yin (2001), o método do estudo de caso é adequado e pode ser usado em pesquisas que respondem a questões do tipo como. A principal abordagem é a quantitativa. A abordagem quantitativa emprega dados quantificados, utilizando para técnicas estatísticas e modelos matemáticos, que podem ou não ser lineares (OLIVEIRA, 1999). Nesta pesquisa, usou-se um modelo não-linear de otimização, baseado na modelagem do problema por meio de uma equação não-linear, derivação desta equação em relação a variável de interesse, igualdade da expressão derivada a zero e isolamento de uma relação que calcule o ponto em que a variável faz com que a equação se iguale a zero.

\section{Gestão de estoques}

O estoque existe devido ao desequilíbrio entre a demanda e o fornecimento (BERTAGLIA, 2003). Estoque deve funcionar como elemento regulador do fluxo de materiais da empresa, isto é, como a velocidade com que chega à empresa é diferente da que sai, há necessidade de certa quantidade de materiais, que hora aumenta hora diminui amortecendo as variações. A gestão de estoques tem importância no papel operacional e financeiro das empresas e merecem um grande cuidado na sua gestão. Sob o ponto de vista operacional, o estoque serve para amortecer as diferenças entre os fluxos da empresa de entrada e saída de materiais. Sob o ponto de vista financeiro, o estoque é investimento e tem custos para mantê-lo na empresa, tais como perdas, manutenção, armazenagem, estoque ainda deve proporcionar retorno de capital. Sabe-se que a manutenção dos estoques custa dinheiro, as empresas devem reduzir os estoques ao máximo sem prejudicar o nível de serviço, (NOVAES; ALVARENGA, 2000).

Neste sentido, para Dias (2005), o importante é a otimização de seu estoque, calculado por meios eficientes de planejamento e controle, minimizando o capital em estoques. Para o autor, um sistema de materiais deve estabelecer uma integração desde a previsão de vendas, passando pelo planejamento de programa-mestre de produção, até a produção e a entrega do produto final. De maneira geral, a integração do sistema de materiais com a função compras exige (ARNOLD, 1999):

(i) especificar as necessidades de compras segundo a política de otimização de estoque; (ii) 
selecionar os fornecedores potenciais e desenvolvê-los; (iii) negociar termos e acordos de entregas e ressuprimentos; (vi) administrar os ciclos de pedidos junto aos fornecedores; (v) mensurar o desempenho dos principais fornecedores; (vi) classificar, certificar e gerenciar os fornecedores segundo as classes de desempenho; e (vii) cooperar com os principais fornecedores selecionados.

A necessidade de manter estoques acarreta uma série de custos às empresas, (MARTINS; CAMPOS, 2006). Simultaneamente, a administração de estoques deve minimizar o capital investido em estoques, pois ele é caro e aumenta continuamente, uma vez que o custo financeiro aumenta (DIAS, 2005). Para Viana (2000), a gestão de estoque visa o gerenciamento de estoque por meio de técnicas que permitam manter equilíbrio como consumo, definindo parâmetros e níveis de ressuprimento e acompanhando a sua evolução. Neste contexto, observa-se que administrar os recursos destinados aos estoques das empresas é uma atividade essencial quando se objetiva o lucro. Teve maior impulso a partir da expansão das atividades logísticas e tem como objetivo conciliar os interesses entre a necessidade de suprimentos e a otimização dos recursos financeiros e operacionais das empresas (GONÇALVES, 2004). Ao conseguir-se otimizar os investimentos em estoques, com negociações e estratégias, dimensionamento dos estoques e projetos de sistemas de distribuição, pode-se ter redução de custos e aumento no lucro (POZO, 2004).

Estoque é um importante elemento na cadeia de suprimentos e pode alterar a eficiência das empresas se não for bem gerenciado (CHOPRA; MEINDL, 2003). A cadeia de suprimentos tem inicio nos fornecedores, passa pelas atividades de transformação e finalmente, após as atividades de distribuição, o produto chega até a revenda e ao consumidor. As empresas podem utilizar a informação como aliado à gestão de estoques, pois pode ser um fator-chave na cadeia de suprimentos, permitindo que a cadeia de suprimentos seja eficiente e responsiva. Hoje em dia, as empresas que contam com administração de materiais integrada aos fornecedores podem garantir mais altos níveis de serviço ao cliente e retorno para empresa.

Um dos elementos desta política é a previsão da demanda, considerada peça importante para entendimento e apoio aos processos de decisão e planejamento dos estoques feito pela gerência. Essa área tem a função de administrar todos os materiais da empresa, dos estoques às instalações, formas e locais de armazenagem em locais seguros e de fácil acesso. Nos dias atuais cada vez mais se houve falar em otimização de estoques, como modo de aumento de eficiência. Os objetivos do gerenciamento de estoques são maximizar os recursos da empresa e fornecer um nível satisfatório de serviço ao cliente ou consumidor (CHOPRA; MEINDL, 2003).

Bertaglia (2003) afirma que a compreensão dos objetivos estratégicos da existência do gerenciamento dos estoques é fundamental para definir metas, tipos de estoque e forma como eles afetam as organizações em suas atividades produtivas de relacionamento com o mercado. Estoques possuem custos, que são importantes para a determinação da política de estoque: custos de 
aquisição, custos de manutenção e custos de falta de estoques (BALLOU, 2006). A gestão de estoques é uma atividade cada vez mais foco de engenheiros, administradores e todas as pessoas envolvidas diretamente no processo produtivo de empresas de produtos e serviços, ela deve coordenar a movimentação de suprimentos com a exigência de operação, prover o material certo, no momento certo com o custo mínimo (BALLOU, 1993).

O gerenciamento de estoques com qualidade garante um bom nível de serviço, que é o resultado de todos os esforços logísticos da empresa no atendimento dos pedidos dos clientes (BALLOU, 1993). O controle de estoques envolve as tarefas de coordenação de fornecedores, condições físicas, armazenamento, distribuição e registro das existências de todas as mercadorias (GURGEL, 2000). O trade-off central geralmente se dá entre eficiência e flexibilidade: o aumento da flexibilidade geralmente exige que a empresa eleve o seu estoque de segurança e mantenha capacidade de reserva para atender a demanda inesperada, ao passo que o aumento da eficiência exige que essas duas reservas sejam reduzidas ao mínimo (TAYLOR, 2009).

Estoque de segurança é o estoque mantido como forma de precaução no caso da demanda real exceder a prevista. Para Bertaglia (2003), o estoque de segurança visa proteger rupturas de estoque, enquanto se espera o recebimento do pedido. Estoques de segurança nunca garantirão $100 \%$ de chances de não haver falta de produto (FLEURY; WANKE; FIGUEREDO, 2009) e pode ser calculado a partir da equação 1 (GARCIA; PEREIRA; OSÓRIO, 2009).

$$
\mathrm{ES}=\mathrm{fs} \times \sigma(1)
$$

na qual:

$\mathrm{fs}=$ fator de segurança (definido como função do nível de serviço estabelecido pela empresa)

$\sigma=$ desvio-padrão da demanda durante o tempo de ressuprimento típico do item.

Determinar a quantidade do estoque de segurança a ser mantido é uma decisão importante, pois envolve a opção entre o custo do excesso de estoque ou custo causado pela perda de vendas (CHOPRA; MEINDL, 2003). O custo dos materiais e produtos comprados pode representar uma parte importante do valor final das vendas das empresas. Por este motivo, a função compras está tipicamente envolvida na negociação e em assegurar a disponibilidade de materiais no momento certo, na quantidade certa na hora certa, com qualidade ao preço justo (GURGEL, 2000). Em muitos casos não é o custo que determina o preço de venda, mas o inverso. O preço de venda necessário resulta na determinação de uma redução do custo de compra e de estoque, principalmente quando estes elementos são parte importante da despesa de operação de uma atividade empresarial (MARTINS; ALT, 2006). Além de outras qualidades essenciais, um agente comprador deverá possuir a de saber prever para prover (FLEURY; WANKE; FIGUEIREDO, 
2009).

Para Pozo (2004), a administração dos estoques é influenciada por diversos fatores e que acarreta benefícios, facilidade e pronto atendimento ao cliente, e custos decorrentes de manter produtos estocados. Encontrar o ponto de equilíbrio entre custos e benefícios decorrentes da existência de estoque torna-se um problema de otimização, estudado pela Pesquisa Operacional. Este campo de conhecimento oferece modelos lineares e não-lineares para cálculo dos níveis de estoques que otimizem a relação entre custos e benefícios (MOREIRA, 2001). Para Pozo (2004), uma das mais importantes decisões gerenciais atitudes é equilibrar custos e benefícios, chegando a uma metodologia de aquisição, padrões de suprimentos e principalmente de atendimento ao cliente.

Quanto maior o tempo de reposição ou mais dificuldade de resposta do fornecedor maior deverá ser o estoque. O lote econômico de compra (LEC) é a quantidade comprada tal que minimize o custo total anual em estoque. Este custo é dado pela equação 2. O lote econômico é dado pela equação 3. A repercussão de um lote econômico no problema de otimização é representada pela Figura 1. Se o tamanho do lote cresce, crescem os custos de estocagem e decrescem os custos de fazer e processar os pedidos. Se o lote decresce, o movimento é oposto. Quando as linhas se encontram, o custo total passa por um mínimo, otimizando o processo de decisão. $\mathrm{O}$ lote econômico foi encontrado por uma técnica não-linear: derivar a equação de custo em relaçao à variável tamanho de lote, igualar a zero e obter o lote. (MOREIRA, 2001).

$$
\begin{gathered}
C T=\frac{A D}{Q}+C D+\frac{Q}{2} i \\
Q=\sqrt{\frac{2 A D}{i C}}
\end{gathered}
$$

nas quais:

$\mathrm{CT}=$ custo total da política de estoque de um item;

$\mathrm{Q}=$ tamanho do lote de compra;

$\mathrm{Q} / 2$ = estoque médio no período;

$\mathrm{A}=$ custo para fazer um pedido (\$/ciclo);

$\mathrm{C}=$ preço unitário por item (\$/unitário);

$\mathrm{i}=$ custo percentual da guarda $(\%$ de $\mathrm{C})$;

$\mathrm{D}=$ demanda (ciclos/período). 


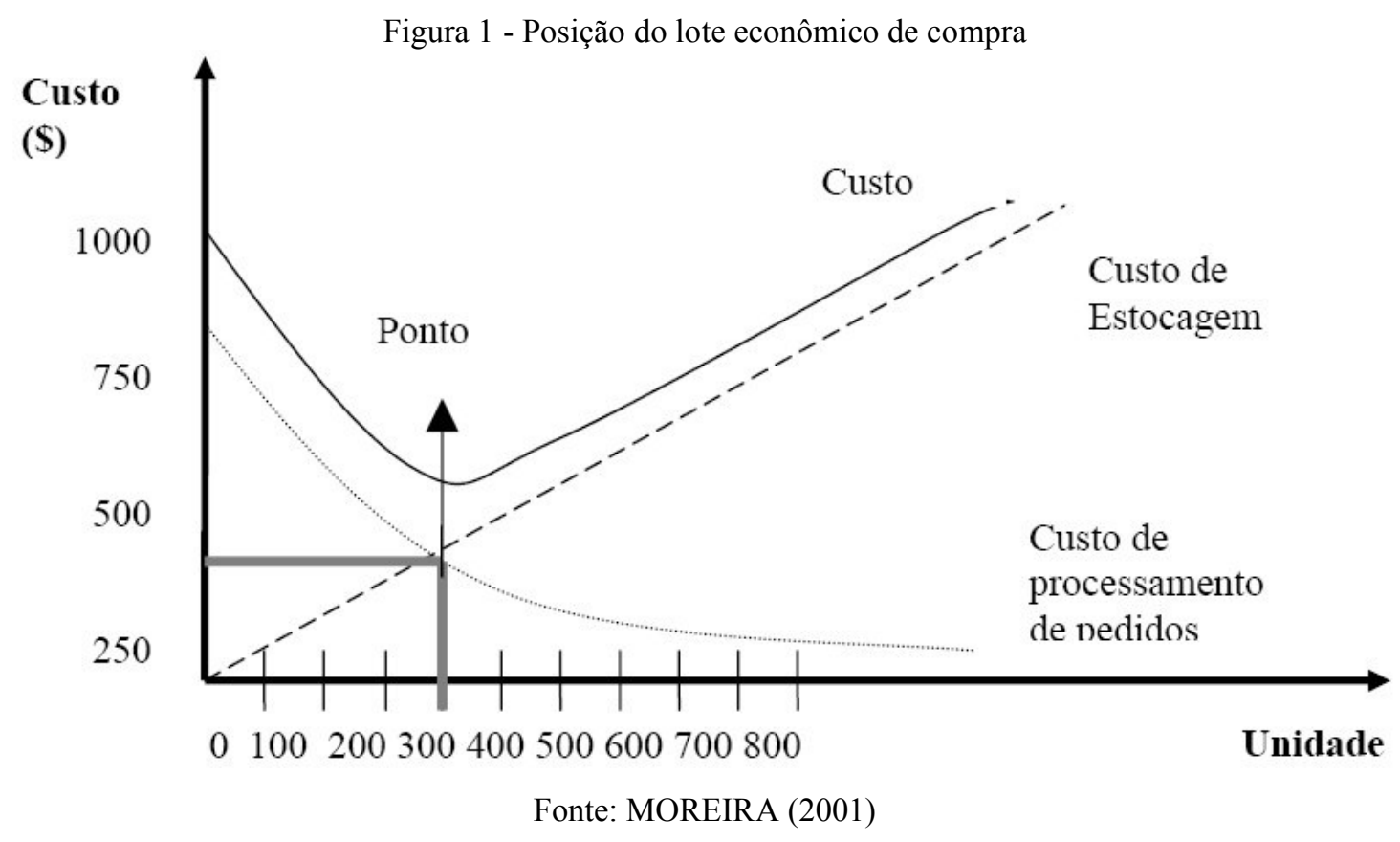

Os custos associados à gestão de estoques podem ser classificados em quatros áreas principais (GARCIA et al., 2006): (i) custos de manutenção dos materiais e das instalações; (ii) custos de fazer e processar os pedido; (iii) custo da compra dos materiais de reposição; e (iv) custos acarretados pelas eventuais faltas de materiais. Os custos de manutenção de estoques são proporcionais à quantidade armazenada e ao tempo de armazenagem. Um destes custos é o custo de oportunidade de uso do capital, que representa a perda que a empresa arca por ter o capital investido em estoques, nao em outro ativo. Os custos de fazer e processar os pedidos referem-se aos custos arcados quando um novo pedido é feito, incluindo as áreas de compras e de sistemas de informação que se mobilizam para realizar a aquisição. Os custos de falta ocorrem quando não existe estoque suficiente para satisfazer a procura dos clientes no momento em que se dá a demanda.

Neste artigo e na equação 2 não foram considerados os custos de falta. Como a empresa fornece principalmente para clientes empresariais, que colocam pedidos e aceitam prazos de entrega, não ocorre falta, podendo no entanto ocorrer atrasos.

\subsection{Política para controle e reposição de estoques de produtos}

Ponto de pedido (PP) é a quantidade que dispara a reposição de estoque virtual quando este alcançá-lo: a quantidade do saldo em estoque suporta o consumo durante o tempo de reposição (DIAS, 2005). O ponto de pedido depende diretamente do consumo médio de materiais e do tempo de ressuprimento (OLIVEIRA; CARNEIRO, 2004). O estoque virtual é a soma do estoque físico com o saldo de fornecimentos já contratados e ainda não recebidos (DIAS, 2005). Sabe-se que a 
manutenção de estoque custa dinheiro, as empresas procuram reduzir seus níveis ao máximo, sem prejudicar o nível de serviço do sistema por falta de produto. O ponto de pedido se dá pela soma da demanda média no tempo de ressuprimento com o estoque de segurança, conforme a equação 4 e seu comportamento ocorre conforme a Figura 2 (MOREIRA, 2001).

$\mathrm{PP}=[$ demanda média no tempo de ressuprimento $]+[$ estoque de segurança $]$

Figura 2 - Comportamento do estoque

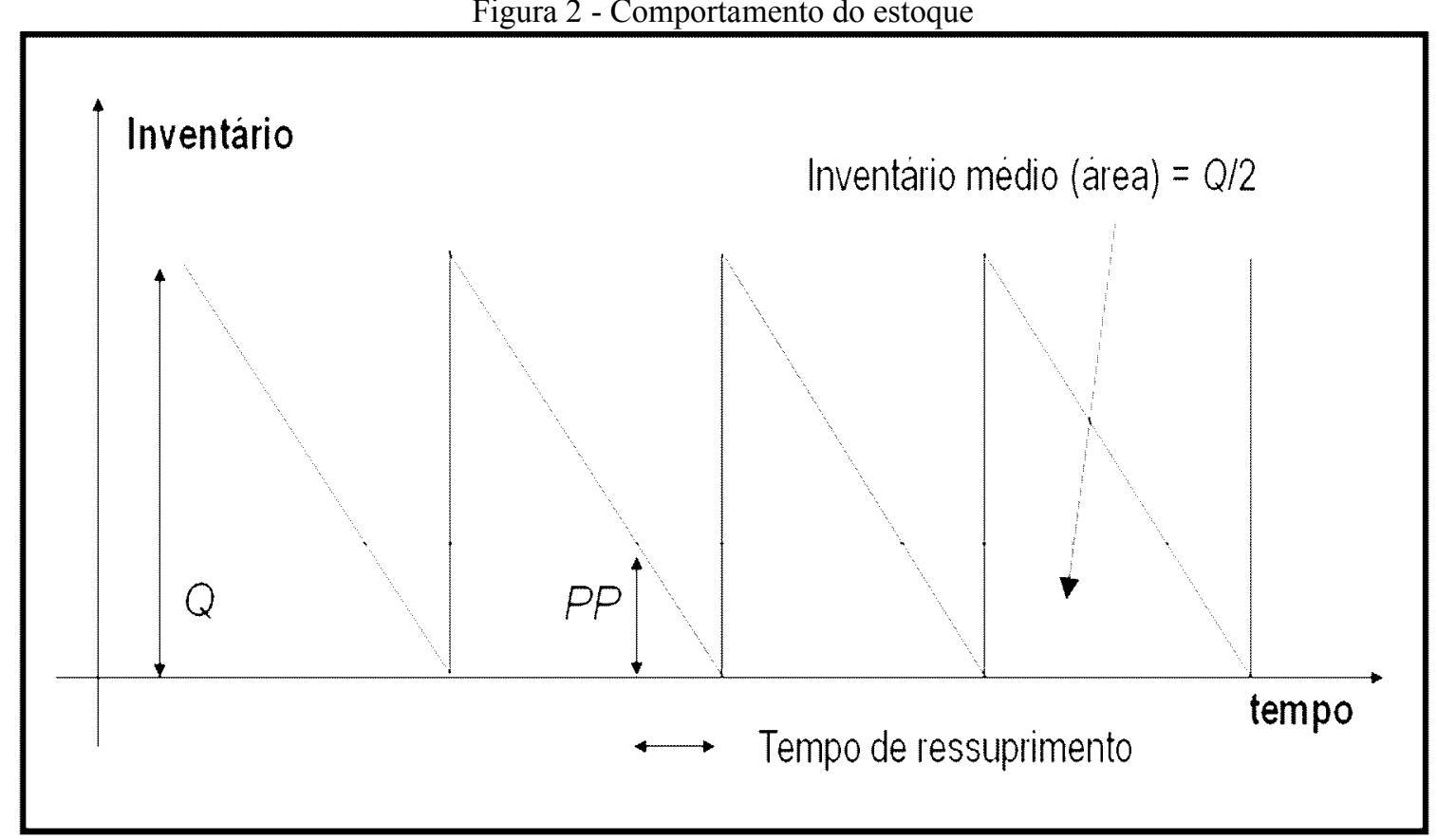

Fonte: MOREIRA (2000)

\section{A pesquisa: metodologia e resultados}

Os procedimentos realizados para esse estudo de caso foram: levantamento de dados na empresa e análise dos dados levantados. Foi foco de estudo da política de estoques a partir do histórico da demanda de quatro itens uma linha de louças sanitárias que a empresa hoje possui no seu mix de produtos. As louças são fabricadas no Espírito Santo - BR, Brasil, a 2.100 quilômetros da empresa estudada, sediada em Alvorada, no Rio Grande do Sul. Atualmente, o fornecedor pratica prazo de reposição típico de um mês para as encomendas recebidas.

Para que o objetivo de pesquisa fosse alcançado, foram realizadas algumas atividades:

- Inventário dos produtos em 01/06/2010;

- Comparação da atual posição de estoques com as políticas de estoques estudadas;

- $\quad$ Levantamento da demanda no período de 01/01/2009 até 31/05/2010;

- Calculado estoque de segurança;

- $\quad$ Determinado ponto de pedido;

- $\quad$ Foi adotada a metodologia de inventário cego e duplo, para melhor confiabilidade 
dos valores de estoques.

O estudo de caso foi baseado nos dados de vendas passadas na empresa a partir de 01/01/2009 até 31/05/2010. Após esse levantamento de vendas, foi possível comparar o nível de estoques atual, com as políticas de estoques presentes nas bibliografias estudadas. Após apurados esses dados foi então proposta uma política de gestão de estoques à diretoria da empresa sob forma de conclusão do trabalho aqui descrito.

A pesquisa se deu devido à necessidade de otimizar estoques. Foram coletados dados preliminares à pesquisa que mostraram que a empresa trabalha com um montante de despesas financeiras somando $2 \%$ do faturamento bruto, sendo que $80 \%$ são devido aos altos níveis de estoques de materiais com baixo giro. Dessa forma, a eficiência da empresa tem sido prejudicada por estoques excessivos. Também foi observado que algumas vendas têm sido perdidas por falta de material para entrega, geralmente devido a atrasos na compra da reposição. Portanto, a empresa tem problemas de excesso e também de falta de estoque. Com isto, se justifica o objetivo de propor uma política baseada em ponto de pedido e em lote de reposição para a empresa. A empresa hoje oferece um mix de 800 itens aproximadamente. Para esta pesquisa foram utilizados quatro itens.

Os dados foram analisados juntamente com a diretoria da empresa, que é responsável pelas compras. $\mathrm{O}$ fornecedor atualmente tem praticado prazos ao redor de um mês para atendimento de pedidos de reposição de produtos. Foram escolhidos para testar e ilustrar a política quatro itens. A Tabela 1 apresenta os dados de demanda destes itens. Como o tempo de reposição médio é de um mês, foram coletadas as demandas médias mensais e calculados os desvios-padrão nos doze meses anteriores à pesquisa, de 01/01/2009 a 31/05/2010.

Tabela 1- Dados de demanda

\begin{tabular}{cccc}
\hline Item & Descrição & Demanda mensal ( $\square$ ) & Desvio padrão ( $\square$ ) \\
\hline 1 & Cuba de Embutir Oval 49 x 32,5 cm - Branco & 21 & 14 \\
2 & Cuba de Embutir Oval 49 x 32,5 cm - Bege & 10 & 7 \\
3 & Cuba de Embutir Oval 39 x 30 cm - Biscuit & 10 & 8 \\
4 & Bacia p/ Caixa Acoplar Thema - Branco & 27 & 10 \\
\hline
\end{tabular}

FONTE: Autoria própria (2010)

A Tabela 2 apresenta os pontos de pedido calculados para os quatro itens, conforme a equação (3). Foi adotado um nível de serviço objetivado de $95 \%$ para este estudo, o que implica um fs $=1,64$ para o cálculo.

Tabela 2 - Cálculo dos pontos de pedido

\begin{tabular}{cccc}
\hline Item & Descrição & $\begin{array}{c}\text { Estoque de segurança ES } \\
\text { (fs x } \square)\end{array}$ & $\begin{array}{c}\text { Ponto de pedido (demanda } \\
\text { média mensal + ES) }\end{array}$ \\
\hline 1 & Cuba de Embutir Oval $49 \times 32,5 \mathrm{~cm}-$ Branco & 23 & 44 \\
2 & Cuba de Embutir Oval $49 \times 32,5 \mathrm{~cm}-$ Bege & 12 & 22 \\
3 & Cuba de Embutir Oval $39 \times 30 \mathrm{~cm}-$ Biscuit & 13 & 23
\end{tabular}


FONTE: Autoria própria (2010)

Por fim, a Tabela 3 apresenta o cálculo dos lotes econômicos de reposição. Têm-se as demandas anuais, obtidas multiplicando-se as demandas médias mensais da Tabela 1 por doze, os custos unitários dos produtos para o atacadista, o custo de fazer um pedido e o custo percentual de guarda dos itens. O custo unitário de fazer um pedido foi obtido dividindo-se o custo organizacional de fazer a compra nos doze meses (sistemas de comunicação e de informação compartilhados mais horas compartilhadas de comprador $=\mathrm{R} \$ 45.107,18$ ) pelo número de itens comprados no período (3.720). O custo da guarda foi obtido dividindo o total gasto com despesas financeiras por adiantamentos e empréstimos para compras mais horas compartilhadas de operador de almoxarifado e despesas com seguros ( $\mathrm{R} \$ 100.600,00)$, pelo total gasto em compras no período (R\$ 7.597.820,00).

Com estes dados, usando a equação (2), calcularam-se os lotes econômicos de compras de reposição da última coluna.

Tabela 3- Lotes econômicos de reposição

\begin{tabular}{cccccc}
\hline Item & Demanda anual & Custo do produto R\$ & A & i\% & LEC \\
\hline 1 & 252 & 32,4 & 12,12 & $1,32 \%$ & 120 \\
2 & 120 & 32,4 & & & 82 \\
3 & 120 & 30,8 & & & 85 \\
4 & 324 & 117,8 & & & 71 \\
\hline
\end{tabular}

FONTE: Autoria própria (2010)

Considerando os lotes econômicos de compra e as demandas anuais, na Tabela 4 apresentam-se as políticas de compras e os números de vezes que cada item será comprado por ano. Por exemplo, o primeiro item terá a seguinte política: sempre que o estoque virtual estiver abaixo de 44 unidades, comprar um lote de 120. Esta política acarretará 2,1 compras por ano, pois a demanda anual esperada é de 252 unidades.

Tabela 4- Políticas de compras de reposição

\begin{tabular}{ccccc}
\hline Item & Demanda anual & PP & LEC & Número de compras anuais \\
\hline 1 & 252 & 44 & 120 & 2,1 \\
2 & 120 & 22 & 82 & 1,5 \\
3 & 120 & 23 & 85 & 1,4 \\
4 & 324 & 43 & 71 & 4,6 \\
\hline
\end{tabular}

FONTE: Autoria própria (2010)

Observa-se na tabela que alguns número de compras anuais são baixos. Existe na atual política de compras da empresa alguns riscos, tais como manutenção de estoque por tempo demasiado e danos aos bens. O risco de obsolescência é pequeno por tratar-se de empresa que comercializa apenas itens básicos, sem design avançado ou inovador. Mesmo que um item seja 
obsoletado, dificilmente o estoque remanescente não será adquirido, pois os materiais são indicados para múltiplas aplicações. Como são itens básicos e nao de moda ou de impacto visual, eventuais diversidades de cores e modelos têm menor importância na política de reposição e a empresa pode lidar bem com um pequeno volume de compras, pois também pode aproveitar eventuais oportunidades oferecidas pelos grandes fabricantes.

Obtidas as políticas da Tabela 4, verificou-se o estoque virtual momentâneo dos quatro itens. Estes são apresentados na Tabela 5, comparados com os pontos de pedido calculados e o lote econômico de reposição. Os itens 1 e 3 possivelmente faltarão antes da chegada de uma eventual reposição. $\mathrm{O}$ item 2 já está em falta. $\mathrm{O}$ item 4 está um pouco acima do lote econômico, o que pode ser aceito em função da existência de um estoque de segurança.

Tabela 5- Situação de estoques para fins de reposição

\begin{tabular}{ccccc}
\hline Item & PP & LEC & Estoque virtual atual & Situação \\
\hline 1 & 44 & 120 & 25 & Vai faltar \\
2 & 22 & 82 & 0 & Em falta \\
3 & 23 & 85 & 19 & Vai faltar \\
4 & 43 & 71 & 87 & Excesso \\
\hline
\end{tabular}

FONTE: Autoria própria (2010)

A tabela mostra algumas das deficiências que a empresa pode estar enfrentando em sua gestão de materiais destinados a estoques. Um item apenas entre quatro está com estoque aceitável, enquanto que os outros três apontam para faltas. É possível que clientes que requeiram estes produtos não sejam atendidos no prazo e na quantidade que benham a solicitar, causando perda comercial à empresa. A perda não se limita à venda que não se confirma, mas se estende também à imagem da empresa, que pode ser prejudicada pelo não-atendimento as demandas de clientes.

A última análise feita diz respeito ao custo total que cada política de estoque implica. A Tabela 6 apresenta o cálculo.

Tabela 6 - Custos implicados pelas políticas de estoque apontadas

\begin{tabular}{ccccccc}
\hline Item & Demanda anual & Custo do produto R\$ & A & i\% & LEC & CT (R\$) \\
\hline 1 & 252 & 32,4 & 12,12 & $1,32 \%$ & 120 & 8.216 \\
2 & 120 & 32,4 & & & 82 & 3.923 \\
3 & 120 & 30,8 & & 85 & 3.730 \\
4 & 324 & 117,8 & & 71 & 38.278 \\
\hline
\end{tabular}

FONTE: Autoria própria (2010)

Na tabela, repetem-se os parâmetros que entram no cálculo do custo tal de uma política de estocagem, aplicada aos quatro produtos selecionados. Custos por eventuais faltas são pouco representativos na atual estratégia da empresa, pois a mesma atende principalmente clientes empresariais (empreiteiras e construtores), que colocam pedidos e aceitam prazos de entrega. Tais 
clientes não demandam elevado nível de serviço e dificilmente comparecem na empresa para comprar um item e levar a pronta entrega, o que praticamente elimina o chamado custo da venda perdida ou da falta de estoque. Na última coluna da tabela apresentam-se os resultados dos cálculos dos custos anuais, por produto. Observa-se que estes são os custos mínimos que são possíveis de serem obtidos, calculados pela equação de otimização do tamanho de lote. Ainda assim, caso a empresa decida reduzir estes custos, as melhores oportunidades são a redução dos custos de fazer e processar pedidos, custos de armazenagem, estes valendo para todos os produtos, e o preço de compra do quarto produto, bem mais elevado do que os demais.

\section{Considerações finais}

O objetivo desse artigo foi abordar e descrever uma proposta de política de gestão de estoque que possa ser utilizada na empresa estudada. A pesquisa foi feita com o intuito de comparar alguns resultados atuais de estoque com resultados obtidos por meio de um modelo de gestão baseado em dois parâmetros, o ponto de pedido, o PP, e o lote econômico de compra, o LEC. Podese concluir que o modelo de gestão de estoque baseado no cálculo do PP e do LEC pode trazer resultados aceitáveis e competitivos, uma vez que mostrou tanto um eventual excesso de compras em alguns quanto a falta de estoque em outro produto. Foi observado que não existe uma definição de ponto de pedido e de tamanho de lote na empresa, ou seja, as compras não são feitas segundo uma política sistematizada.

Com isso têm-se então uma oportunidade de melhoria de gestão na cadeia de suprimentos da empresa, que seria um acordo com o fornecedor para determinação de condições de ressuprimento mais adequadas e mais sistematizadas. Também fica como sugestão de melhoria a implantação do estoque de segurança, visto que traz benefícios à empresa nos casos de picos de demanda durante o tempo de ressuprimento.

Outra alternativa de gestão de ressuprimentos seria a revisão periódica. Neste caso, os custos de transporte seriam otimizados, pois haveria eventual aproveitamento de rotas de entregas já existentes. Para esta estratégia, seria necessário considerar a existência de transportadores e de rotas que incluam as regiões dos fornecedores e de eventuais parceiros que contribuam para a maior utilização dos veículos. A revisão periódica abre uma nova possibilidade de trade-off estratégico: para se ter menos estoque, é necessária estrutura de transporte mais rápido e melhores sistemas de informações para obter previsões mais acuradas. Remete-se à continuidade de pesquisa a investigação acerca desta alternativa.

\section{Abstract}


This article presents a case study on Inventory Management in a wholesaler in the business of civil construction. The work was structured based on the review of literature on the concepts of Inventory Management. We presented the forms of inventory management present in bibliographies and a comparison with the current situation of the company's inventory levels in order to propose a policy of stocks. The use of inventories is made at the time of replenishment and is important because it enables better customer service and improves the competitiveness of the company relative to its competitors, but must be managed constantly to avoid unnecessary expenses. The management method was applied to four products from a line of bathroom fixtures that the company has in its product mix.

Key-words: inventory management; service level; time of replenishment; point of order; economic lot quantity.

\section{Agradecimentos}

Agradecemos a empresa e os seus gestores que aceitaram participar da pesquisa e o CNPq pelo financiamento de parte desta pesquisa.

\section{Referências}

ARNOLD, J. Administração de materiais: uma introdução. S. Paulo: Atlas,1999.

ALVARENGA, A.; NOVAES, A. Logística Aplicada - suprimento e distribuição física. São Paulo: Edgard Blücher, 2000.

BALLOU, R. Logística Empresarial: transporte, administração de materiais, distribuição física. São Paulo: Atlas, 1993.

BALLOU, R. Gerenciamento da cadeia de suprimentos / logística empresarial. Porto Alegre: Bookman, 2006.

BERTAGLIA, P. Logística e gerenciamento da cadeia de abastecimento. São Paulo, 2003.

CHOPRA, S.; PETER, M. Gerenciamento da cadeia de suprimentos: estratégia, planejamento. São Paulo: PrenticeHall, 2003.

DIAS, M. Administração de materiais. São Paulo: Atlas, 2005.

ELLRAM, L.; CARR, A. Strategic purchasing: a history and review of literature. International Journal of Purchasing and Materials Management, v.30, n.2, p.10-18, 1994.

FLEURY, P.; WANKE, P.; FIGUEREDO, K. Logística empresarial: a perspectiva brasileira. São Paulo: Atlas, 2009.

GARCIA, L.; PEREIRA, M.; OSÓRIO, W. Gestão dos parâmetros de estoque: estudo de caso de itens de medicamentos em farmácias hospitalares e convencionais. Revista Gestão Industrial, v.05, n.01: p.109-121, 2009.

GARCIA, E. et al. Gestão de estoques: otimizando a logística e a cadeia de suprimentos. Rio de Janeiro: E-papers Servicos Editoriais Ltda., 2006.

GONÇALVES, P. Administração de materiais. R. Janeiro: Campus, 2004.

GURGEL, F. Logística industrial. São Paulo: Atlas, 2000.

KUNIGAMI, F.; OSÓRIO, W. Gestão no controle de estoque: estudo de caso em montadora automobilística. Revista Gestão Industrial, v.05, n.04: p.24-41, 2009.

MARTINS, P.; ALT, P. Administração de materiais e recursos patrimoniais. São Paulo: Saraiva, 2006. 
MOREIRA, D. Administração da produção e operações. São Paulo: Pioneira Thomson Learning, 2001.

OLIVEIRA, R.; CARNEIRO, S. Elaboração e implementação de um modelo de administração de estoque baseado em faixa de ressuprimento. In: ENCONTRO NACIONAL DE ENGENHARIA DE PRODUÇÃO, 24, 2004, Florianópolis. Anais... Florianópolis: ABEPRO, 2004.

OLIVEIRA, S. Tratado de metodologia científica. São Paulo: Pioneira. 1999.

POZO, H. Administração de recursos materiais e patrimoniais: uma abordagem logística. São Paulo: Atlas. 2004.

TAYLOR, D. Logística na cadeia de suprimentos: uma perspectiva gerencial. São Paulo, Pearson Addison-Wesley, 2005.

VIANA, J. Administração de materiais: um enfoque prático. São Paulo: Atlas, 2000.

YIN, R. Estudo de caso: planejamento e métodos. Porto Alegre: Bookman, 2001.

\section{Dados dos autores:}

Nome completo: Diego Telles Provin

Filiação institucional: UNISINOS

Departamento: Engenharia de Produção Mecânica

Função ou cargo ocupado: Engenheiro

Endereço completo para correspondência (bairro, cidade, estado, país e CEP): Av. Unisinos, 950, São Leopoldo, RS, 93020-000

Telefones para contato: 51 3591-1122

e-mail:diegoprovin@bol.com.br

Nome completo: Miguel Afonso Sellitto

Filiação institucional: UNISINOS

Departamento: Programa de Pós-Graduação em Engenharia de Produção e Sistemas

Função ou cargo ocupado: Professor e pesquisador

Endereço completo para correspondência (bairro, cidade, estado, país e CEP): Av. Unisinos, 950, São Leopoldo, RS, 93020-000

Telefones para contato: 51 3591-1122

e-mail:sellitto@unisinos.br

Enviado em: $15 / 07 / 2010$

Aprovado em: 20/06/2011 